\title{
PEMBIASAAN PEMBACAAN PALI WACANA PARITTA DI PUSAT PENDIDIKAN DAN LATIHAN SIKKHADAMA SANTIBHUMI TANGERANG
}

\author{
Iin Suwarni \\ STAB Negeri Sriwijaya Tangerang Banten \\ iin.suwarni@yahoo.co.id
}

\begin{abstract}
The problem examined in this study was the Habit of Päli Wacana Paritta at the Sikkhadama Santibhumi Training Center in Tangerang. Beginning to hear the Päli paritta discourse in several monasteries/cetiya there were differences caused by the local dialect. In fact, the difference in reciting the paritta in Pāli wacana is not a mistake as the dialect of each person cannot be forced. However, actually this can be attempted so that uniformity occurs in the context of the paritta discourse, because actually there is the same Päli grammar. So the purpose of this study was to describe the habituation of the paritta discourse at the Sikkhadama Santibhumi Training Center in Tangerang.

This research is a qualitative descriptive study. The subjects of this study were Sangha Bhikkhu, Romo/Ramani, administrators, SMB supervisors and Sikkhadama Pusdiklat Santibhumi people. The object in this study was the habituation of the discourse at the Sikkhadama Santibhumi Training Center in Tangerang. Data collection techniques by means of interviews, documentation and observation. Qualitative data analysis using the Miles and Huberman models. Through this research, the researcher described the phenomenon of the habituation of the paritta discourse at the Sikkhadama Santibhumi Training Center in Tangerang.

The results of this study indicate that the process of habituation of the paritta discourse went smoothly with the guidance of the Sangha Bhikkhu. Even though the process is always given the procedure for reading. This is because the people who come from different Buddhist backgrounds. The determinants of the level of success in the implementation of the pitta of the paritta discourse include the guidance of the devotional service. With good worship leaders, the people will follow the parish discourse well.
\end{abstract}

Keywords: habituation, Pāli discourse, paritta. 


\begin{abstract}
ABSTRAK
Masalah yang diteliti dalam penelitian ini adalah pembiasaan Pāli Wacana Paritta di Pusat Pendidikan dan Latihan (Pusdiklat) Sikkhadama Santibhumi Tangerang. Berawal dari mendengar pembacaan Pāli wacana paritta di beberapa wihara/cetiya ternyata terdapat perbedaan yang disebabkan oleh dialek setempat. Sebenarnya perbedaan cara membaca Pāli wacana paritta bukan merupakan kesalahan karena memang dialek tidak dapat dipaksakan. Namun, sebenarnya hal tersebut dapat diupayakan agar terjadi keseragaman dalam Pāli wacana paritta, karena sesungguhnya terdapat tata bahasa Pāli yang sama. Tujuan penelitian ini mendeskripsikan pembiasaan pembacaan Pāli wacana paritta di Pusdiklat Sikkhadama Santibhumi Tangerang.

Penelitian ini merupakan penelitian deskriptif kualitatif. Subjek penelitian ini adalah Bhikkhu Sangha, Romo/Ramani, pengurus, pembimbing Sekolah Minggu Buddha (SMB), dan umat Pusdiklat Sikkhadama Santibhumi. Objek penelitian ini adalah pembiasaan pembacaan Pāli wacana di Pusdiklat Sikkhadama Santibhumi Tangerang. Teknik pengumpulan data dengan cara wawancara, dokumentasi, dan observasi. Analisis data kualitatif menggunakan model Miles \& Hubberman. Melalui penelitian ini, peneliti mendeskripsikan fenomena pembiasaan pembacaan Pāli wacana paritta di Pusdiklat Sikkhadama Santibhumi Tangerang.

Hasil penelitian ini menunjukkan bahwa proses pembiasaan pembacaan Päli wacana paritta berjalan dengan lancar atas bimbingan Bhikkhu Sangha. Meskipun dalam prosesnya selalu diberikan arahan tata cara pembacaannya. Hal tersebut dikarenakan umat yang hadir dari latar belakang Agama Buddha yang berbeda. Penentu tingkat keberhasilan dalam pelaksanaan pembiasaan pembacaan Pāli wacana paritta di antaranya oleh pemandu puja bakti. Dengan pemimpin puja bakti yang baik maka umatnya akan mengikuti pembacaan Päli wacana paritta dengan baik.
\end{abstract}

Kata kunci: pembiasaan, Pāli wacana, paritta. 


\section{PENDAHULUAN}

Agama Buddha di Indonesia memiliki keberagaman yang unik, dibandingkan dengan Agama Buddha di beberapa negara Buddhis. Keunikan yang ditunjukkan dengan berbagai mazhab yang dianut oleh masing-masing umatnya. Keberagaman mazhab yang ada, tampak dari tata cara melaksanakan puja bakti. Puja bakti yang dilaksanakan oleh setiap mazhab dengan mengikuti dari mana tradisi tersebut berasal.

Sebagaimana dijumpai di Tangerang, umat Buddha di beberapa wihara memiliki ciri khas yang berbeda-beda berdasar mazhab yang diyakini oleh setiap umatnya. Dengan demikian umat Buddha memiliki keberagaman dalam hal membaca naskah Bahasa Päli. Sebenarnya terdapat tata cara Pāli Wacana sama, karena terdapat tanda baca dalam naskah Paritta Pāli sehingga berbagai pihak dapat membaca naskah dengan cara membaca yang sama. Namun, pada kenyataannya tata cara yang sudah ditetapkan dalam tata Bahasa Pāli sulit untuk diikuti oleh sebagian umat Buddha di beberapa tempat, sehingga tetap membaca naskah Pāli dalam Paritta dengan cara baca yang berbeda. Hal tersebut di antaranya disebabkan karena dialek setempat yang susah untuk diubah.

Tata cara membaca naskah Pāli yang tidak tepat sesuai dengan tanda bacanya, tidak dapat dikatakan salah sebagaimana dijelaskan oleh Bhante Atthadhiro pada saat observasi pada tanggal 15 April 2018. Bahkan di negara Buddhis pun karena dialek bahasa setempat yang sulit untuk ditinggalkan, pengucapan pali wacana paritta menjadi tidak sesuai penulisannya, contohnya adalah Namo Tassa dibaca menjadi Namo Tasse. Hal tersebut dikarenakan dialek setiap wilayah yang sulit untuk diubah mengikuti aturan yang seharusnya. Umat Buddha di Indonesia memiliki perbedaan cara membaca naskah Paritta Pāli dengan umat Buddha di beberapa negara Buddhis. Naskah paritta Pāli sudah dapat dipastikan sama persis, namun karena dialek yang sulit untuk diubah akhirnya pembacaan pāli wacana menjadi berubah.

Untuk dapat membiasakan pembacaan Pāli wacana paritta sesuai dengan tanda baca dapat dilakukan berbagai upaya. Dari beberapa wihara atau cetiya telah mengupayakan agar umat Buddha dapat membacakan paritta Pāli sesuai dengan tata bahasa Pāli. Upaya tersebut di antaranya dengan memberikan pelatihan, 
orientasi, dhammaclass, dan ada juga yang melakukan upaya tersebut melalui pembiasaan bahkan melalui lomba-lomba agar generasi penerus semangat dalam membiasakan cara membaca pāli wacana paritta. Bahkan, beberapa organisasi mengadakan pelatihan cara membaca Pāli wacana paritta yang dipandu langsung oleh Bhikkhu Sangha, namun tidak banyak umat Buddha yang berminat untuk mengikuti kegiatan tersebut (Wawancara dengan umat Buddha di beberapa wihara/cetiya).

Sehubungan dengan pembiasaan pembacaan Pāli wacana yang dilaksanakan oleh umat Buddha di Pusdiklat Buddhis Sikkhadama Santibhumi Tangerang, penulis ingin mengetahui bentuk pelaksanaannya, respons dari umat Buddha dan hambatan yang dialami dalam rangka pelaksanaan pembacaan pembiasaan Pāli Wacana tersebut dengan melakukan penelitian berjudul "Pembiasaan Pembacaan Pāli Wacana Paritta oleh Umat Buddha di Pusat Pendidikan dan Latihan Buddhis Sikkhadama Santibhumi Tangerang".

\section{Pembiasaan}

\section{TINJAUAN PUSTAKA}

Secara etimologi, kata pembiasaan tersusun dari kata "biasa" yang mendapatkan prefiks "pe-" dan sufiks "-an". Dalam Kamus Besar Bahasa Indonesia, "biasa" adalah lazim atau umum, seperti sedia kala, sudah merupakan hal yang tidak terpisahkan dari kehidupan sehari-hari. Kemudian prefiks "pe-" dan sufiks "-an" menunjukkan arti proses. Dengan demikian, pembiasaan dapat diartikan dengan proses membuat sesuatu atau seseorang menjadi terbiasa.

Pembiasaan yaitu sebagaimana yang dikemukakan oleh para ahli, di antaranya menurut Abdullah Nasih Ulwan, "metode pembiasaan adalah cara atau upaya yang praktis dalam pembentukan (pembinaan) dan persiapan anak. Menurut Ramayulis, "metode pembiasaan adalah cara untuk menciptakan suatu kebiasaan atau tingkah laku tertentu bagi anak didik." Ahli lain menyatakan bahwa "metode pembiasaan adalah cara yang dilakukan dalam pembentukan akhlak dan rohani yang memerlukan latihan yang continue setiap hari."

Dari beberapa definisi di atas, terlihat adanya kesamaan pandangan walaupun memiliki ungkapan yang berbeda-beda. Namun pada prinsipnya, mereka sepakat bahwa pembiasaan 
merupakan salah satu upaya pendidikan yang baik dalam pembentukan manusia dewasa. Oleh karena itu, dapat diambil suatu pengertian bahwa yang dimaksud metode pembiasaan adalah sebuah cara yang dipakai pendidik untuk membiasakan anak didik secara berulang-ulang sehingga menjadi kebiasaan yang sulit ditinggalkan dan akan terus terbawa.

Ciri khas metode pembiasaan adalah kegiatan yang berupa pengulangan berkali-kali dari suatu hal yang sama. Pengulangan ini sengaja dilakukan berkali-kali supaya asosiasi antara stimulus dengan suatu respons menjadi sangat kuat. Dengan demikian, terbentuklah pembiasaan cara membaca yang tepat sesuai dengan tata bahasa pali yang berlaku. Pembiasaan selain menggunakan perintah, suri teladan, dan pengalaman khusus, juga menggunakan hukuman. Tujuannya agar umat Buddha memperoleh kebiasaan-kebiasaan baru yang lebih tepat dalam päli wacana.

\section{Pāli Wacana}

Setiap bahasa memiliki karakteristik tersendiri, dimulai dari Bahasa Pāli tidak diketahui secara pasti kapan dan di mana digunakan, bahkan para ahli bahasa juga tidak tahu secara pasti mengenai perkembangan Bahasa Päli tersebut. Namun hal tersebut tidak menjadi masalah untuk dirisaukan, yang terpenting adalah semangat untuk mempelajari dan melestarikan Bahasa Päli. Sebagaimana dijelaskan oleh Cunda J. Supandi (2010: 7) yang dimaksud dengan Bahasa Pāli adalah bahasa kitab suci, yaitu bahasa yang digunakan dalam penulisan Kitab Suci Agama Buddha (Tipitaka). Jadi bukan merupakan bahasa yang digunakan dalam percakapan sehari-hari.

Saat ini mungkin hanya sejumlah bhikkhu tua di beberapa negara Buddhis, seperti Srilanka, Burma, Thailand saja yang masih mampu menggunakannya sebagai bahasa percakapan dalam kehidupan sehari-hari. Mempelajari suatu bahasa menjadi lebih mudah jika bisa dipraktikkan langsung dalam percakapan, tetapi sungguh sulit menggunakan Bahasa Päli sebagai bahasa percakapan sehari-hari. Namun demikian, apabila kita banyak membaca Pāli Text maka kita akan semakin banyak memiliki perbendaharaan kata.

Dengan membaca naskah Pāli juga akan mengetahui bentuk mana yang dipakai dalam percakapan sehari-hari dan yang mana yang digunakan dalam bentuk sastra atau cerita kuno. Begitu juga 
apabila terbiasa melihat tafsiran kata pali yang begitu beragam juga akan mengetahui kata mana yang boleh diletakkan pada awal kalimat dan mana yang tidak, walaupun keduanya mempunyai arti dan kasus yang sama.

\section{Paritta}

Umat Buddha dalam melaksanakan puja bakti dengan membacakan paritta atau sutra/mantra sesuai untuk menunjukkan penghormatan kepada Buddha dan Bodhisattva. Paritta adalah khotbah Buddha yang merupakan suatu perlindungan yang kuat bilamana bisa dihafal (Dhammadiro, 2013). Jadi paritta dibacakan atau dilafalkan ditujukan bukan untuk memohon atau meminta suatu hal. Namun lebih kepada akan mendapatkan perlindungan bagi pembacanya apabila memiliki keyakinan yang kuat dan dibacakan dengan kesungguhan dan tentunya memiliki kumpulan karma baik yang mendukung.

Pada saat membacakan paritta, pikiran harus ditujukan, dipusatkan, pada makna paritta tersebut sehingga pada saat kesadaran (sati-sampajanna) menjadi kuat, pikiran (citta) bersatu dengan kebajikan, bersih dari kilesa, sebaliknya penuh dengan cinta kasih (metta) dan kebenaran Dhamma (sacca) (Sangha Theravada Indonesia, 2010: 12). Jadi mengulangi paritta merupakan kondisi untuk mempercepat masaknya buah karma baik yang telah dibuat, sedangkan buah karma yang tidak baik terhambat masaknya, kecuali akusala garuka kamma, yang merupakan karma yang paling berat. Inilah yang dimaksud perlindungan dalam membacakan paritta sehingga jelas saat membacakan paritta selesai, tidak ada permohonan meminta sesuatu hal.

\section{Respons}

Respons dalam kamus Sosiologi Antropologi adalah aktivitas atau tanggapan (reaksi) terhadap suatu kondisi (situasi stimulus) di mana kondisi itu harus dihadapi (Yacub Al-Barry, 2001: 134). Wasty Soemanto (1998: 26) mengartikan respons yang berarti tanggapan, yang merupakan serapan yaitu apa yang diterima oleh panca indra, bayangan dalam angan-angan, pendapat, pandangan, sambutan dan reaksi.

Menurut Berlo (Rusmialdi, 1983: 57), respons adalah segala sesuatu yang dilakukan seseorang terhadap rangsangan atau akibat merasakan rangsangan. Respons adalah reaksi yang dilakukan seseorang terhadap rangsangan atau perilaku yang 
dihadirkan oleh rangsangan. Selanjutnya respons dapat dibagi dalam dua katagori, yaitu: overt response dan convert response. Overt response adalah respons yang dapat dilihat orang lain, sedangkan convert response adalah respons yang tidak dapat dilihat oleh orang lain, sifatnya adalah pribadi.

Menurut paradigma definisi sosial Webber (Ritzer, 2003: 146) tentang tindakan sosial, respons adalah tindakan yang penuh arti dari individu sepanjang tindakan itu memiliki makna subjektif bagi dirinya dan diarahkan pada orang lain. Tindakan sosial yang dimaksud dapat berupa tindakan yang bersifat membatin atau bersifat subjektif yang mungkin terjadi karena pengaruh dari situasi atau dapat juga merupakan tindakan pengulangan dengan sengaja akibat dari situasi serupa.

Berdasarkan beberapa penjelasan tentang respons dapat disimpulkan bahwa respons merupakan perilaku, sikap atau reaksi sebagai suatu tanggapan atau tindakan yang dilakukan yang merupakan akibat adanya rangsangan-rangsangan yang terjadi sebelumnya. Menurut Sarlito Wirawan (2002: 97) respons memiliki dua model yaitu: respons positif dan negatif.

Dalam hal respons positif yaitu tentang respons umat Buddha terhadap pembiasaan pembacaan Pāli Wacana, apabila respons mereka positif, itu berarti mendukung dan setuju dengan adanya pembiasaan pembacaan Pāli Wacana. Dalam hal respons negatif yaitu tentang respons umat Buddha terhadap pembiasaan pembacaan Päli Wacana, itu berarti mereka tidak mendukung dan tidak setuju dengan adanya pembiasaan pembacaan Pāli Wacana.

\section{Hambatan}

Bahasa Pali adalah bahasa ketiga setelah bahasa ibu dan bahasa Indonesia bagi pembelajar bahasa Pāli di Indonesia. Belajar bahasa asing dari asal ke bahasa sasaran tentunya ada perbedaan. Oleh karenanya dalam belajar bahasa asing diperlukan totalitas dalam penguasaannya. Keterlibatan seluruh aspek fisik, intelektual, dan emosional sangat diperlukan untuk mencapai keberhasilan sepenuhnya dalam proses belajar melalui media pembelajaran yang ada. Hal ini berlaku untuk semua orang yang belajar bahasa asing.

Pada dasarnya terdapat dua aspek pokok dalam pembelajaran bahasa asing yaitu mempelajari bahasa asing dan belajar mengungkapkan diri dalam bahasa tersebut (Hardjono, 1998: 90). Sebagai hasil mempelajari teori bahasa seseorang akan 
memperoleh pengetahuan tentang fonologi, leksikal, dan tata bahasa atau sering disebut tentang pengetahuan suatu bahasa. Hasil mempelajari segi praktis bahasa seseorang akan memperoleh keterampilan dalam menggunakan bahasa secara lisan maupun tulisan. Merujuk pada tujuan awal seseorang belajar bahasa yaitu untuk bisa menggunakannya sebagai alat komunikasi dengan baik dan benar, sekaligus sarana untuk bertukar pikiran.

Faktor lain adalah perbedaan-perbedaan individu. Dalam hal ini titik berat perbedaannya adalah cara individu tersebut dalam memperoleh bahasa asing, serta cara mereka mereduksinya. Umur, bakat, dan motivasi merupakan faktor penyebab keberagaman pemerolehan dan kemampuan dalam mereduksi bahasa asing. Dari segi umur, dapat dibedakan menjadi dua yaitu anak-anak dan orang dewasa. Anak-anak pada umumnya jauh lebih cepat berhasil dalam pembelajaran bahasa. Bakat dalam berbahasa yang dimiliki pembelajar dalam mempelajari bahasa merupakan salah satu faktor utama penentu keberhasilan dalam pembelajaran bahasa, karena bakat terpisah dari inteligensia. Motivasi menjadi faktor penentu keberhasilan karena perbedaan motivasi juga akan mempengaruhi kecepatan dalam mempelajari bahasa asing termasuk dalam penguasaan pembacaan päli wacana paritta ini.

\section{METODE}

Metode penelitian dipilih agar mendapatkan data yang relevan dengan masalah yang diteliti. Dengan demikian perlu dipilih metode yang tepat sesuai dengan penelitian yang akan dilakukan. Pemilihan metode yang tepat diharapkan dapat diperoleh suatu hasil penelitian yang dapat dipertanggungjawabkan kebenarannya. Metode merupakan cara utama yang dipergunakan untuk mencapai suatu tujuan (Surakhmad, 2004: 131). Penelitian ini merupakan jenis penelitian deskriptif kualitatif. Peneliti memilih pendekatan fenomenologis yang bertujuan untuk mengetahui fenomena esensial partisipan dalam pengalaman hidupnya (Sugiyono, 2013: 229). Melalui penelitian ini, peneliti mendeskripsikan fenomena pembiasaan pembacaan pāli wacana paritta di Pusdiklat Sikkhadama Santibhumi Tangerang. 


\section{HASIL DAN PEMBAHASAN}

\section{Bentuk pelaksanaan pembiasaan pembacaan Pāli wacana paritta}

Peneliti memperoleh data mengenai bentuk pelaksanaan pembacaan Päli wacana paritta dengan diawali dari definisi Pāli wacana. Seluruh pihak yang terkait dengan perannya dalam pelaksanaan pembacaan päli wacana paritta telah memahami definisi pāli wacana. Mengenai tata Bahasa Pāli juga telah dipahami dengan baik. Dalam proses pembiasaan pembacaan Pāli wacana paritta pihak Pusdiklat belum menjalin kerja sama dengan pihak luar, namun para Bhikkhu Sangha yang mahir dalam bidang tersebut telah secara intensif memberikan arahan dan koreksi pada waktu-waktu tertentu. Jadwal yang tidak menentu ini karena keterbatasan waktu yang dimiliki oleh para bhikkhu yang setiap saat terdapat jadwal mengisi dhammadesana di berbagai wihara atau cetiya di Tangerang dan sekitarnya bahkan sampai di luar Jakarta, Bogor, Depok, Tangerang, Bekasi (Jabodetabek), maka dalam pembiasaan pembacaan päli wacana kurang mendapatkan perhatian penuh dari para bhikkhu.

Pusdiklat menjalin hubungan baik dengan organisasiorganisasi di bawah binaannya Sangha Theravada Indonesia, di antaranya Wanita Theravada Indonesia (Wandani). Pengurus Wandani yang menguasai pembacaan päli wacana paritta diminta agar sesekali memberikan pelatihan. Sekitar tiga tahun yang lalu juga pernah diadakan pali wacana paritta oleh Bhante Khemadiro dan ini juga sudah merupakan waktu yang lama.

Dari bentuk pembiasaan pembacaan Pāli wacana Paritta diharapkan akan dapat melestarikan Bahasa Pāli sebagai bahasa kitab suci Agama Buddha. Di samping itu, bentuk pelaksanaan dari pembiasaan pembacaan Pāli Wacana Paritta akan membiasakan agar umat Buddha mampu mengucapkan paritta dan sutta dengan benar. Upaya ini juga menjadi dasar agar Bahasa Pāli dapat diucapkan dengan benar sehingga arti dari isi paritta tidak mengalami kesalahan terjemahan.

\section{Respons pihak-pihak terkait terhadap pelaksanaan pembacaan Pāli wacana paritta}

Pembiasaan pembacaan Pāli wacana paritta di Pusdiklat Sikkhadama Santibhumi menerima respons yang sangat positif dari berbagai pihak yang terkait. Hal ini dibuktikan dengan dukungan berbagai pihak agar pāli wacana paritta itu dilestarikan 
karena ini merupakan bagian dari naskah pāli ajaran Buddha yang harus dipertahankan keasliannya.

Anggota sangha menegaskan secara gamblang bahwa pembacaan pāli wacana paritta harus selalu dilestarikan, terlepas dari hal tersebut adalah budaya dari mazhab Theravada namun secara lebih luas alasannya karena naskah Bahasa Pāli harus dilestarikan, termasuk bagaimana cara membacanya. Jika sering membaca pāli wacana paritta maka akan paham makna yang sebenarnya. Sebagaimana dicontohkan oleh Bhante Atthadhiro pada saat beliau agak ragu dengan terjemahan dari sebuah sutta maka beliau akan mencari naskah dalam Bahasa Pāli/naskah aslinya, kemudian beliau mencari terjemahannya. Hal ini dilakukan untuk meminimalkan kesalahan pemahaman minimal bagi dirinya yang selanjutnya dibagikan kepada umat.

Respons dari romo/ramani sangat positif bersedia melayani umat jika ada yang berlatih mempersiapkan diri menjadi pemimpin puja bakti. Para romo/ramani dengan setia menanti dan menginformasikan untuk memberi arahan mengenai pembacaan pāli wacana paritta dengan benar. Namun umat masih memiliki motivasi yang minim, sehingga sangat sedikit umat yang berkesadaran diri untuk belajar.

Para dayakasabha sangat mendukung dan mengharapkan keseragaman cara membaca päli wacana paritta saat puja bakti. Dalam hal ini dayakasabha saat menjadi pemimpin puja dengan kesungguhan memberikan teladan pembacaan pāli wacana paritta yang sesuai. Dengan demikian umat yang datang diharapkan dapat membiasakan cara membaca päli wacana dengan benar. Demikian pula para pembimbing Sekolah Minggu Buddha kelas remaja mengharapkan agar para siswa memiliki rasa percaya diri dan khidmat dalam melantunkan pembacaan päli wacana paritta.

Para umat sesungguhnya antusias mengikuti pembiasaan pembacaan päli wacana paritta namun terkadang masih terkendala dengan kemampuan dirinya. Beberapa umat mengaku tata cara membaca pāli wacana harus dilestarikan, karena jika tidak maka ajaran Buddha dapat hilang di masa yang akan datang. Dengan demikian umat tersebut memiliki kesadaran diri untuk melestarikan pembacaan päli wacana paritta. 


\section{Hambatan yang dialami oleh beberapa pihak terkait pelaksanaan pembacaan Pāli Wacana Paritta}

Pembiasaan pembacaan pāli wacana paritta di Pusdiklat Sikkhadama Santibhumi dapat terlaksana dengan baik, namun masih terdapat hambatan yang dapat menghalangi kelancaran dalam pembacaan pāli wacana tersebut. Hambatan pertama yang dialami adalah keberadaan umat yang datang silih berganti dari berbagai wihara dan ada beberapa dari mazhab yang awalnya tidak membacakan päli wacana paritta. Dengan demikian perlu diadakan penjelasan secara umum atau untuk umat yang baru yang masih belum memahami pembacaan päli wacana sehingga secara perlahan akan dapat mengikuti.

Hambatan yang kedua adalah berhubungan dengan pemimpin puja bakti yang menjadi pemandu bagi umat, namun tidak semua pemimpin puja bakti telah mahir melantunkan pembacaan päli wacana paritta. Apabila pemimpin puja bakti telah menguasai pembacaan pāli wacana paritta maka umat akan dapat mengikuti dengan lebih baik, karena pemandunya juga benar. Namun di saat ada pemimpin puja bakti yang belum menguasai pembacaan pāli wacana paritta, maka umat akan kacau dalam mengikuti pali wacana paritta saat puja bakti. Dalam hal ini perlu dilakukan pelatihan atau arahan terlebih dahulu bagi umat yang akan menjadi pemimpin puja bakti.

Pihak dayakasabha Pusdiklat sangat berterima kasih kepada umat yang bersedia menjadi pemimpin puja bakti, karena tidak banyak umat yang bersedia menjadi pemimpin puja bakti. Hal tersebut dikarenakan umat merasa belum mampu dan tidak percaya diri dan belum bersedia untuk diberikan arahan pelantunan pali wacana paritta. Harapan ke depan dari Bhikkhu Sangha, romo/ramani, dayakasabha, pembimbing SMB dan para umat terhadap pembiasaan pembacaan päli wacana paritta agar dilaksanakan pelatihan pembacaan pāli wacana paritta secara intensif sehingga umat Buddha secara perlahan akan dapat melantunkan paritta dengan sesuai tanda baca.

Pembiasaan pembacaan Päli Wacana merupakan sebuah upaya untuk membuang hal-hal yang kurang sesuai dan seiring berjalannya waktu upaya tersebut berhasil merubah menjadi hal yang sesuai dengan tata aturan yang seharusnya dijadikan acuan. Pembiasaan pembacaan Pāli wacana ini dilakukan oleh umat Buddha di Pusdiklat Sikkhadama Santibhumi Tangerang, agar 
umat Buddha di Pusdiklat tersebut memiliki kebiasaan yang benar dalam membacakan paritta dengan Bahasa Pāli.

Penelitian yang serupa dilakukan oleh Nurul faizah Lestari berkaitan dengan "Program Pembiasaan Membaca Al Qur'an Kelas V di MI Muhammadiyah Watubelah Banjarnegara", bahwa untuk penguasaan bahasa upaya yang dapat dilakukan dengan melakukan pembiasaan secara terus-menerus. Penelitian sejenis untuk memperkuat bahwa pembiasaan akan membawa perubahan ke arah yang lebih baik dilakukan oleh Lilik Musfirotun Ni'mah tentang "Pengaruh Metode Pembiasaan Membaca Al Qur'an terhadap Kemampuan Menghafal Surat-Surat Pendek Siswa MTs N Petarukan.

\section{Kesimpulan}

\section{PENUTUP}

Berbagai tahapan dalam penelitian ini telah dilalui, mulai dari memaparkan latar belakang penelitian ini sampai dengan pemaparan hasil penelitian. Untuk selanjutnya peneliti akan menyimpulkan hasil penelitian tentang pembiasaan pembacaan pāli wacana paritta di Pusdiklat Sikkhadama Santibhumi Tangerang, sebagai berikut:

1. Pembiasaan pembacaan pāli wacana paritta di Pusdiklat Sikkhadama Santibhumi secara umum terlaksana dengan mengacu pada tata Bahasa Pāli yang berlaku dan terlaksana secara terus-menerus untuk selalu melakukan perbaikan.

2. Pembiasaan pembacaan päli wacana paritta mendapat respons positif, hal ini terbukti dengan dukungan dari berbagai pihak terkait untuk tetap melestarikan naskah pāli di antaranya dengan pembiasaan pembacaan pāli wacana paritta.

3. Pembiasaan pembacaan Pāli wacana paritta mengalami beberapa hambatan, di antaranya terdapat sedikit narasumber baik secara intensif maupun berkala untuk memberikan pelatihan pāli wacana paritta khususnya untuk yang akan memimpin puja, umat yang hadir selalu mengalami penambahan sehingga selalu mengalami kendala dalam proses pembacaan päli wacana dan tidak semua pemandu puja bakti telah menguasai pāli wacana paritta meskipun telah dibimbing terlebih dahulu. Namun itu juga sudah beruntung ada yang bersedia mau menjadi pemimpin puja bakti sebagai penuntun pembacaan pāli wacana paritta bagi seluruh umat. 


\section{Saran}

Dengan adanya hasil penelitian ini, sebagaimana telah disimpulkan di atas, maka peneliti akan mengemukakan beberapa saran sebagai berikut:

1. Bagi pihak pusdiklat, hasil penelitian ini hendaknya dapat menyusun program pelatihan pembacaan pāli wacana paritta khususnya bagi yang akan memimpin puja dan bagi para Dharmaduta.

2. Bagi institusi, hasil penelitian ini akan dapat mendorong institusi untuk mengagendakan kegiatan yang berhubungan dengan pembiasaan pembacaan pāli wacana paritta bagi pihak luar kampus atau menjadikan mahasiswa sebagai duta pembacaan pāli wacana paritta.

3. Bagi peneliti lain, dengan adanya keterbatasan dalam penelitian ini, diharapkan untuk mengadakan penelitian sejenis lebih lanjut dengan mengambil wilayah penelitian yang lebih luas, dan selanjutnya akan dapat menemukan solusi untuk mengatasi hambatan yang dihadapi.

\section{DAFTAR ACUAN}

Arikunto, Suharsimi. 2006. Prosedur Penelitian: Suatu Pendekatan Praktik. Jakarta: PT Rineka Cipta.

Nawawi, Hadari. 1999. Metode Penelitian Bidang Sosial. Yogyakarta: Gajah Mada University Press.

Slamet, Y. 2006. Metode Penelitian Sosial. Surakarta: UNS Press.

Sugiyono. 2009. Metode Penelitian Kuantitatif dan Kualitatif dan RED. Bandung: Alfabeta.

Sukardi. 2004. Metodologi Penelitian Pendidikan. Jakarta: Bumi Aksara.

Supandi, J. Cunda. 2010. Tata Bahasa Pali. Jakarta: Medio Vidyacardhana Samuha (Grup Pengembang Pengetahuan).

Surada, I Made. 2006. Pelajaran Bahasa Sanskerta. Surabaya: Paramita.

Usman, Husaini, \& Akbar, Purnomo Setiady. 2004. Metodologi Penelitian Sosial. Jakarta: Bumi Aksara.

Yayasan Sangha Theravada Indonesia. 2013. Paritta Suci. Bekasi: Percetakan Bocah Marga Jaya. 